\title{
Investigating the influence of topographic irregularities and two-dimensional effects on surface ground motion intensity with one- and two-dimensional analyses
}

\author{
G. Ç. Ínce ${ }^{1}$ and L. Yılmazoğlu ${ }^{2}$ \\ ${ }^{1}$ Division of Civil Engineering, Department of Geotechnical Engineering, Faculty of Engineering, Aksaray University, \\ 68100 Aksaray, Turkey \\ ${ }^{2}$ Aksaray University, Division of Civil Engineering, Department of Geotechnical Engineering, 68100 Aksaray, Turkey
}

Correspondence to: G. Ç. İnce (gokcecicekince@gmail.com)

Received: 24 October 2013 - Published in Nat. Hazards Earth Syst. Sci. Discuss.: 6 December 2013

Revised: - - Accepted: 9 June 2014 - Published: 18 July 2014

\begin{abstract}
In this work, the surface ground motion that occurs during an earthquake in ground sections having different topographic forms has been examined with one and two dynamic site response analyses. One-dimensional analyses were undertaken using the Equivalent-Linear Earthquake Response Analysis (EERA) program based on the equivalent linear analysis principle and the Deepsoil program which is able to make both equivalent linear and nonlinear analyses and two-dimensional analyses using the Plaxis 8.2 software. The viscous damping parameters used in the dynamic site response analyses undertaken with the Plaxis 8.2 software were obtained using the DeepSoil program. In the dynamic site response analyses, the synthetic acceleration over a 475year return period representing the earthquakes in Istanbul was used as the basis of the bedrock ground motion. The peak ground acceleration obtained different depths of soils and acceleration spectrum values have been compared. The surface topography and layer boundaries in the 5-5 cross section which cuts across the study area west to east were selected in order to examine the effect of the land topography and layer boundaries on the analysis results, and were flattened and compared with the actual status. The analysis results showed that the characteristics of the surface ground motion change in relation to the varying local soil conditions and land topography.
\end{abstract}

\section{Introduction}

The damage to structures that occurs during an earthquake is not only related to the superstructure but also to the following significant factors: the earthquake characteristics and local soil conditions. The characteristics of earthquake waves may change while passing through different types of soil and this may increase the earthquake forces that impact on the structures situated on the surface of the ground. Likewise, the earthquake waves may change the characteristics of the ground surface while passing through the soil. Local soil conditions have a significant effect on the amplitude and frequency features, thus the inertia forces of the ground acceleration have an effect on structures during an earthquake. Therefore, the behaviour of the layers which constitute the foundation of the soil should be examined before the construction of structures (Ansal, 1994, 1999).

Determining the behaviour of soil layers during an earthquake is one of the important problems encountered in earthquake engineering. The increase in the amplitudes of the earthquake waves while passing through the soil layers close to the surface is defined as soil amplification. The significant factors which affect ground amplification include the dynamic characteristics such as bedrock depth, thickness and types of soil layers on bedrock, shear modulus and damping ratio, and local effects such as variation of these characteristics by depth and deformation, lateral irregularities of soil layers and topographic characteristics (Haşal, 2009; Assimaki and Jeong, 2013; Hough et al., 2010). 


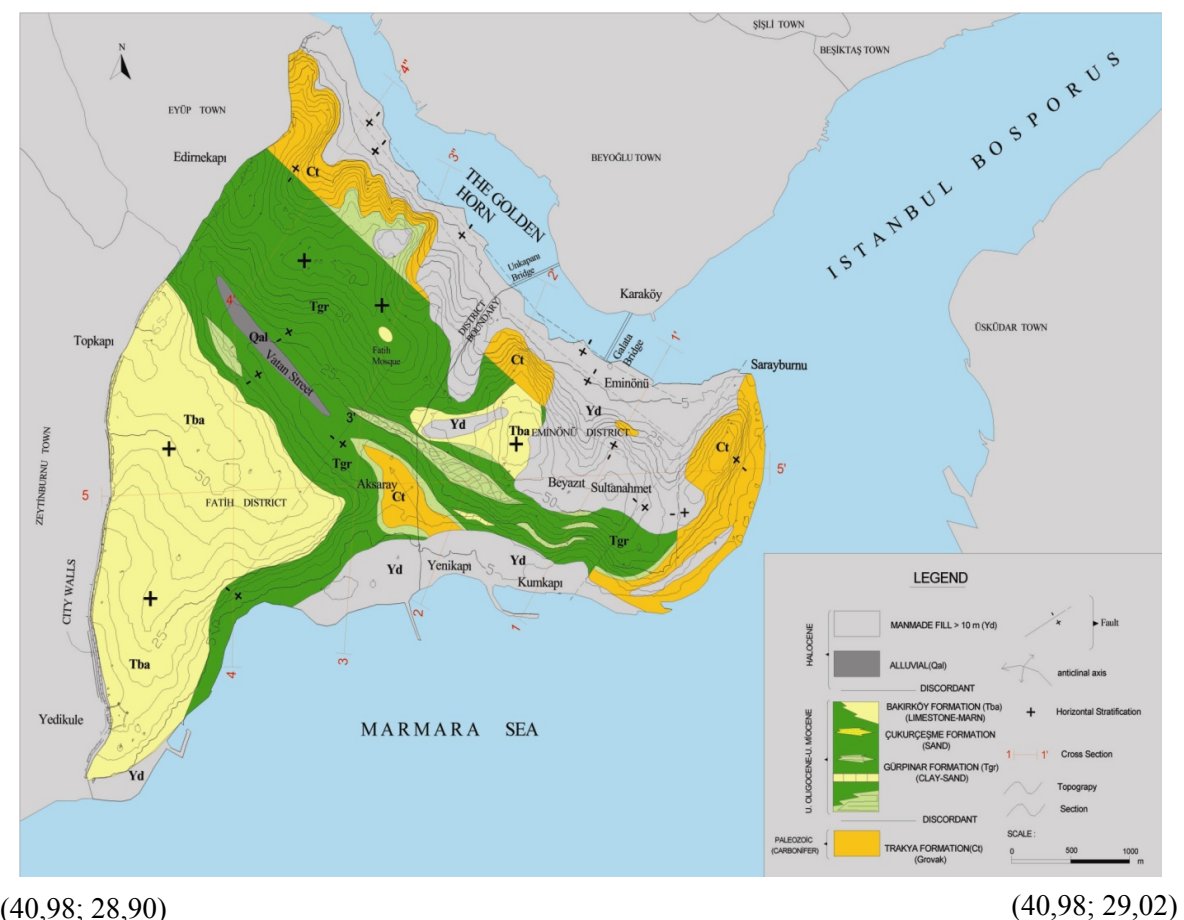

Figure 1. Geological map containing the five cross sections used in the analysis (Ince et al, 2008).

The shear strength of a ground element that is under the influence of repeated stresses resulting from earthquake forces can be defined in two ways and in two stages. The first definition refers to dynamic shear strength and is considered to be the value of the repeated stress amplitude that causes unit deformation amplitudes that rapidly increase or exceed a definite limit value. The second definition is related to the static shear strength which is found as a result of the repeated stress. The general result from work in the literature is that the shear stresses from higher magnitude earthquakes may give rise to major deformations and landslides. Another result is that the major deformations arising from the repeated stress applications may cause softening and the effective stresses are decreased through the increase in pore water pressure, and thus the shear strength is reduced (Ansal et al., 1995).

The calculation methods developed for the dynamic analysis of soils are generally defined in terms of one, two or three dimensions, depending on the requirement of the problem to be resolved. Since for the two- and three-dimensional analyses two- or three-dimensional geometry of layers in the ground sections is required, the one-dimensional approach is often preferred. However, in the one-dimensional dynamic analysis of soils, the surface topography, slope of layers and the effect of the limited width of layers are ignored. The fact that the soils horizontally have a limited width causes the wave motion transformations in the valley edges, thus the frequency content of the ground motion and its effect on the surface may change from the middle of valleys towards edges. However, the effects of the second and even the third dimension emerge in narrow valleys, edges of wide valleys and hillsides (Kale, 2008; Alım, 2006).

\section{Geology and topography of the region}

This work was undertaken within the area known as the historical peninsula of Istanbul, as shown in Fig. 1.

\subsection{Geology}

The geological map (Fig. 1) and selected sections used in this work were derived from a previous scientific study (İnce et al., 2008) in which geological surveys were carried out in and around the investigation field and from the work undertaken in which they obtained data from 125 shallow and deep drillings and investigation trenches in the area. Figure 1 shows two distinct outcropping formations in the study area that are covered with layers of alluvium and artificial fill. The older of the two formations is the Lower Carboniferous Trakya formation, which constitutes the bedrock in the area and is composed of interbedded sandstone (graywacke), siltstone and claystone. The other group comprises units seated unconformably on the Trakya formation and consists of Upper Oligocene-Upper Miocene deposits composed of interbedded sand, clay and carbonates. The Upper 


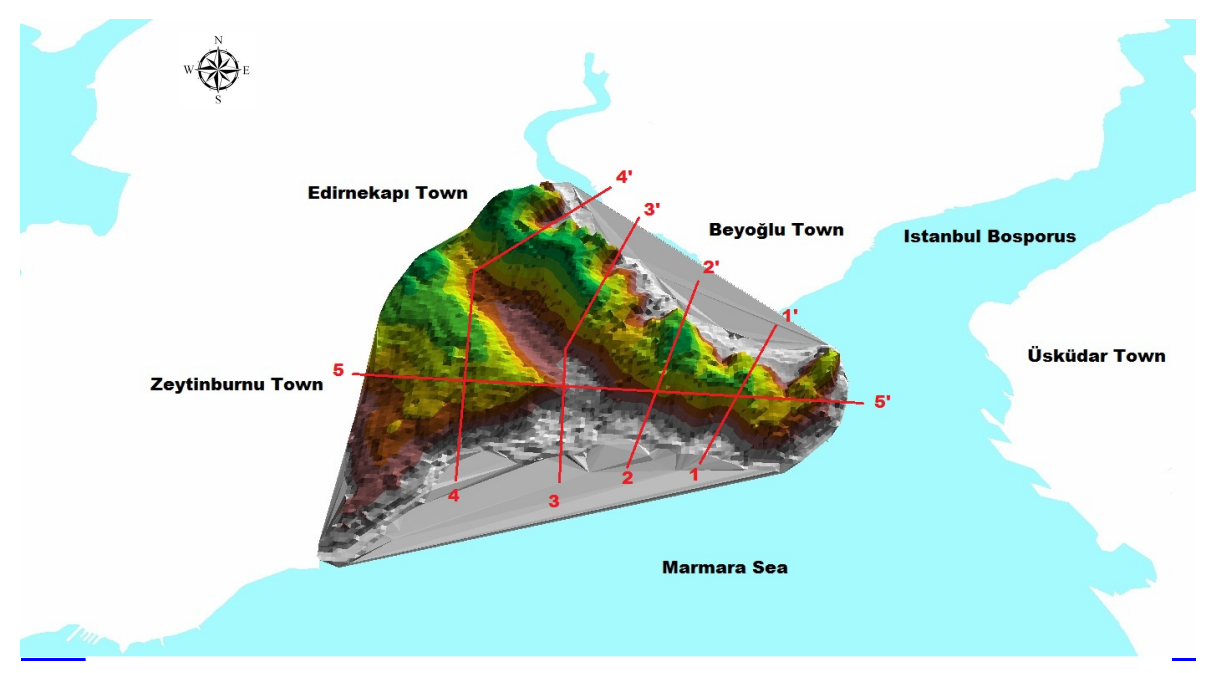

Figure 2. Three-dimensional image of the five sections analysed in the study.

Oligocene-Upper Miocene deposits cover extensive areas both within the study area and in other parts of the European side of Istanbul. These deposits start in depositional sequence with interbedded clay and sand, later continuing with intercalations of gravelly sand, and, in the upper levels, interbedded marl and limestone due to increased carbonate content (as seen in the Gürpınar, Çukurçeşme, Güngören, Bakırköy, and Belgrad formations) (Yildirim and Savaşkan, 2003).

\subsection{Topography}

The peninsula which constitutes the investigation field is bounded by the Golden Horn in the north, the Istanbul Bosphorus in the east and the Sea of Marmara in the south. This peninsula consists of three ridges. The Edirnekap1-Fatih-Beyazıt and Topkap1-Aksaray ridges lie in a northeast-southeast direction and are separated by the Yenibahçe stream bed (Vatan Avenue). The highest part of the Edirnekapı-Fatih-Beyazit ridge reaches $+75 \mathrm{~m}$ around Edirne and the ridge of Topkap1-Aksaray is $+55 \mathrm{~m}$ high. The third ridge is Sarayburnu-Sultanahmet, which lies in a northeast-southwest direction reaching a height of $+45 \mathrm{~m}$ near Sarayburnu. Upright topography is observed in the places where the greywacke rocks belonging to the Trakya formation are located, and the broad and almost-horizontal ridge plains are found where Bakırköy formation marl limestone is situated. This is due to the partial resistance of the formation against abrasion, and the slopes increase where the Gürpınar formation, composed of green clays, surfaces.

The arcview program was used to generate a DEM of the study area using height data at intervals of $50 \mathrm{~m}$ (Fig. 2).

\subsection{The analysed cross sections}

As shown in Fig. 1, the study area was divided into five cross sections which are detailed below.

\subsubsection{Section 1-1'}

This is the smallest section, about $2500 \mathrm{~m}$ long in a northeast-southwest direction, situated between the quarters of Eminönü and Kumkapı located in the farthest eastern part of the section. The section consists of bedrock which is greywacke at the bottom. There are coastal sediments with a thickness of $40 \mathrm{~m}$ in the sea of the Golden Horn to the north. The artificial layers of fill with a thickness of $40 \mathrm{~m}$ in the sea are adjacent to the estuary (Golden Horn) sediments. There are clayey levels of the Gürpınar formation reaching a thickness of $80 \mathrm{~m}$ in the middle of the section and partly including layers of sand. There are alluvial sediments with a thickness of $10 \mathrm{~m}$ on the coastline in the south. The top layer is fully covered with artificial layers of fill. These fills are generally composed of construction waste or marble fragments. Figure 3 shows section $1-1^{\prime}$ with points $1 \mathrm{~A}, 1 \mathrm{~B}, 1 \mathrm{C}, 1 \mathrm{D}, 1 \mathrm{E}$ and $1 \mathrm{~F}$, where the analyses were made.

\subsubsection{Section 2-2'}

This section runs from east of the Unkapanı Bridge in the north to Yenikapı in the south, a distance of approximately $2820 \mathrm{~m}$. The greywacke called Lower Carboniferous old and the Trakya formation forming the bedrock of the region and consisting of grey, brown, multi-crackled, and thin- to medium-layered sandstones, siltstones, clay stones and shale are quite close to the surface in this section and have even partly surfaced. The artificial fills in the coastal region to the north and south reach a thickness of $30-40 \mathrm{~m}$ in the sea. In the middle of the section, the artificial fill thickness from bedrock to surface is $10 \mathrm{~m}$. The stack called the Gürpınar formation sits discordantly on the Trakya formation. It is composed of plentiful fissures, excessively consolidated clays, clay stones and sand lenses of a maximum $50 \mathrm{~m}$ in thickness. The Bakırköy formation forming the upper levels of 


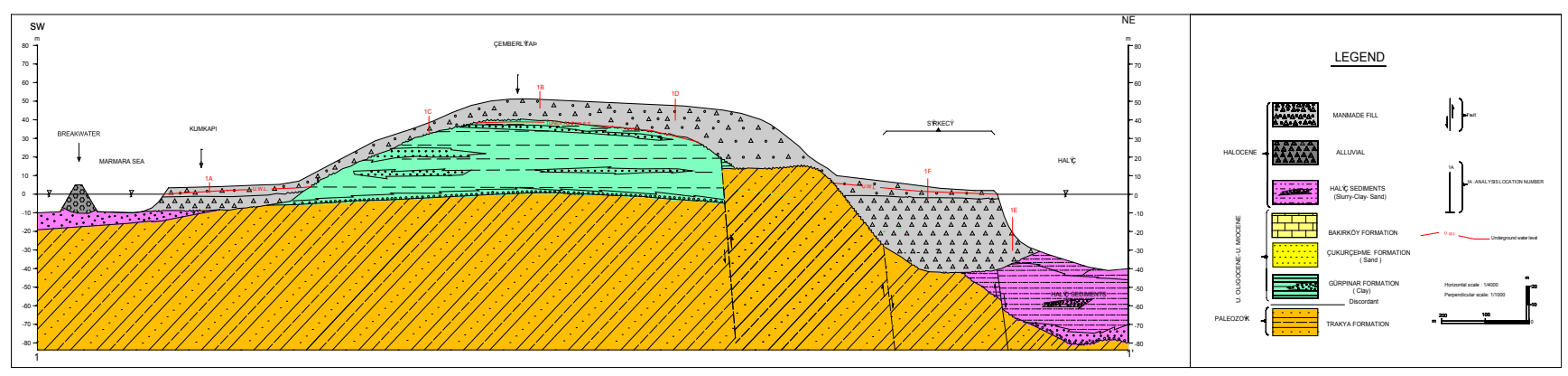

Figure 3. The location of the points on the 1-1' cross section where the 1-D and 2-D analyses were performed (Ince et al., 2008).

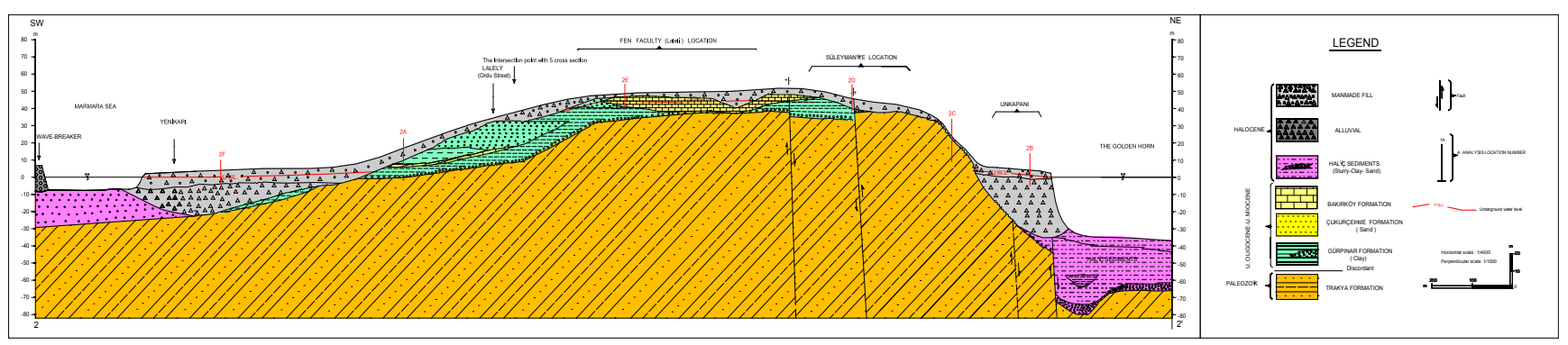

Figure 4. The location of the points on the 2-2' cross section where the 1-D and 2-D analyses were performed (Ince et al., 2008).

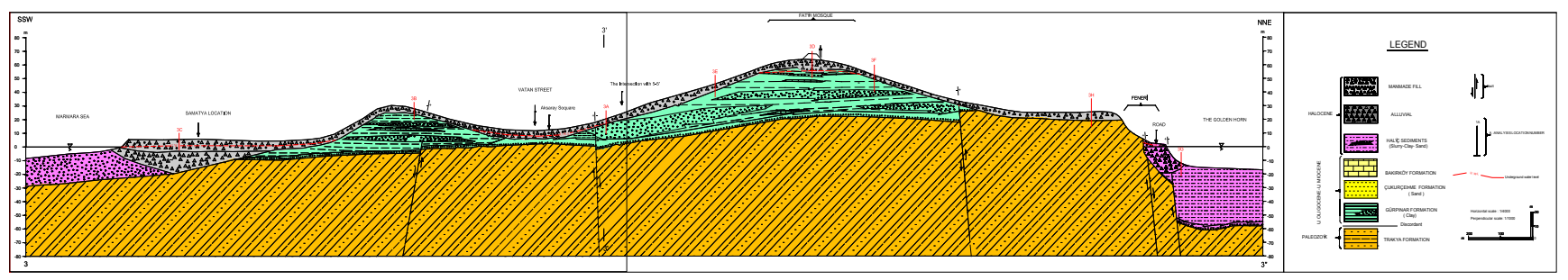

Figure 5. The location of the points on the 3-3' cross section where the 1-D and 2-D analyses were performed (Ince et al., 2008).

the Gürpınar formation is about $20 \mathrm{~m}$ underneath the artificial fills on hilly plains in the section. In Fig. 4, section 2-2' is shown with the $2 \mathrm{~A}, 2 \mathrm{~B}, 2 \mathrm{C}, 2 \mathrm{D}, 2 \mathrm{E}$ and $2 \mathrm{~F}$ points, where the analyses were made.

\subsubsection{Section 3-3'}

This section has a length of $3840 \mathrm{~m}$ and intersects with the ridges of Edirnekapı-Fatih-Beyazıt and Topkap1-Aksaray and the Yenibahçe stream bed (Vatan Avenue) where the slopes end and flat areas begin at the lower levels. There are estuary coastal sediments in the sea in the north and alluvial sediments in the south. The clays of the Gürpınar formation thickness sitting on the bedrock greywacke discordantly are about $60-70 \mathrm{~m}$ under the hilly sides. The thickness of artificial fills is approximately $10 \mathrm{~m}$. In Fig. 5, section $3-3^{\prime}$ is shown with points $3 \mathrm{~A}, 3 \mathrm{~B}, 3 \mathrm{C}, 3 \mathrm{D}, 3 \mathrm{E}, 3 \mathrm{~F}, 3 \mathrm{G}$ and $3 \mathrm{H}$, where the analyses were made.

\subsubsection{Section $4-4^{\prime}$}

This section with a length of approximately $4920 \mathrm{~m}$ is in the farthest western part of the investigation area. In this section, which has thick clayey levels, the thickness of the Gürpınar formation reaches $140 \mathrm{~m}$. As in section 3-3', the high places of the Edirnekapı-Fatih-Beyazıt and TopkapıAksaray ridges and the high levels of the Yenibahçe stream bed are located in this section. The limestone levels of the Bakırköy formation with a thickness of $30-35 \mathrm{~m}$ are placed in the upper levels of the Gürpınar formation in the western part of the section. The artificial fill is about 5-10 m thick in the top levels. In Fig. 6, section 4-4' is shown with points $4 \mathrm{~A}$, $4 \mathrm{~B}, 4 \mathrm{C}, 4 \mathrm{D}, 4 \mathrm{E}, 4 \mathrm{~F}, 4 \mathrm{G}, 4 \mathrm{H}, 4 \mathrm{I}, 4 \mathrm{~J}$ and $\mathrm{K}$, where the analyses were made.

\subsubsection{Section 5-5'}

This section is the longest, at about $5580 \mathrm{~m}$. It lies in an east-west direction and ends at Sarayburnu in the west and 


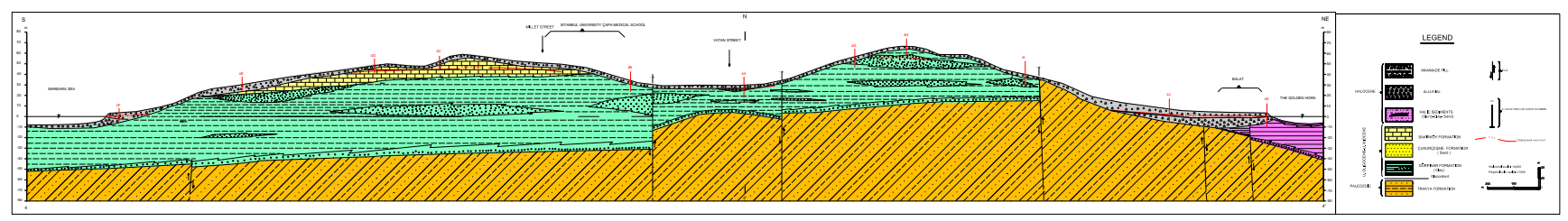

Figure 6. The location of the points on the 4-4' cross section where the 1-D and 2-D analyses were performed (Ince et al., 2008).

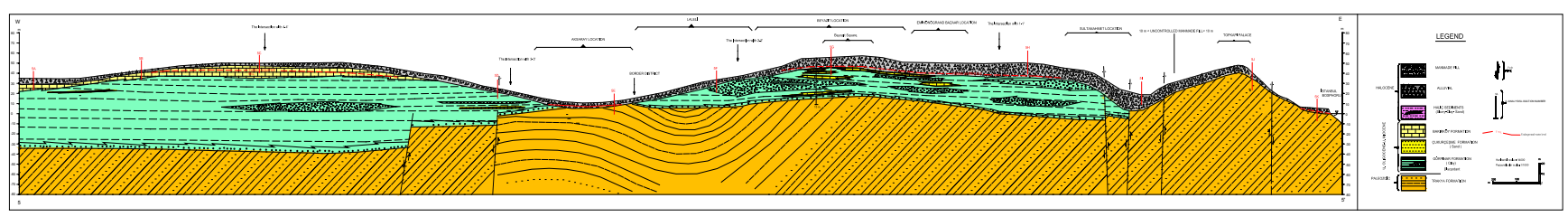

Figure 7. The location of the points on the 5-5' cross section where the 1-D and 2-D analyses were performed (İnce et al., 2008).

Zeytinburnu in the east. The bedrock surfaces just underneath the greywacke artificial fill on the hilly plains where the Topkapı Palace is situated. The Gürpınar formation thickness lies at approximately $140 \mathrm{~m}$ on the bedrock in the east of the section, and the Bakırköy formation on this stack is $25 \mathrm{~m}$. The thickness of the Gürpınar formation within the borders of Eminönü in the west of the section is about $50-60 \mathrm{~m}$. The Bakırköy formation is just visible, as seen in this section. The fill layers situated at the top levels are $30 \mathrm{~m}$ deep in the valley. In Fig. 7, section 5-5' is shown with points $5 \mathrm{~A}, 5 \mathrm{~B}$, $5 \mathrm{C}, 5 \mathrm{D}, 5 \mathrm{E}, 5 \mathrm{~F}, 5 \mathrm{G}, 5 \mathrm{H}, 5 \mathrm{I}, 5 \mathrm{~J}$ and $5 \mathrm{~K}$, where the analyses were made.

\section{One- and two-dimensional analyses}

\subsection{One-dimensional analysis}

When a fault line cracks below the ground surface, object waves are emitted from the source in all directions and when they reach the borders of different geologic units they are reflected and refracted. Since the transmission speed of the wave units in the shallow depth is slower than deeper ones, the inclined beams colliding with the layer boundary are generally refracted towards a more vertical position. The refractions that occur until the beam reaches the ground surface cause them to be refracted mostly in a direction close to the vertical. One-dimensional ground reaction analyses are based on the assumption that all the borders are horizontal and that the ground reaction generally results from the waves (SH waves) emitted vertically from the bedrock. In the one-dimensional ground reaction analysis, the ground and bedrock surfaces are considered to have an infinite horizontal extent.

In this study, one-dimensional analyses were carried out at the following four points: heel, skirt and top of the hillside together with the hilly plain. These points were selected in accordance with the Equivalent-Linear Earthquake Response Analysis (EERA) and DeepSoil computer programs, the field topography and the formations (Table 1). EERA (Bardet et al., 2000) is a computer program prepared in Excel according to the content of Shake (Schnabel et al., 1972), which is a computer program that is widely used in geotechnical earthquake engineering. In this analysis method, it is accepted that the nonlinear behaviours of grounds can be represented approximately by the damped linear elastic model. However, the stress-deformation characteristics of the ground are defined by the shear modulus $(G)$ and equivalent damping ratios $(D)$ changing by unit deformation level $(\gamma)$. The behaviour is accepted as resulting from the shear wave emitting vertically from the bedrock to the surface. The fact that the shear modulus and damping depend on deformation is considered, with an equivalent linear method based on the average effective unit deformations calculated for each layer. The G/Gmax and damping relations depending on deformation and belonging to all formations used in EERA are collectively shown in Figs. 8 and 9. Also, the minimum and maximum values of the unit volume weight, material type and shear wave speeds belonging to the formations are given in Table 2.

The Deepsoil program undertakes analyses in both frequency and time. It can make both linear and equivalent analyses concerning frequency, and both linear and nonlinear analyses concerning time. In this study, equivalent linear and nonlinear analysis methods were used for the Deepsoil analyses. In the nonlinear analysis producing analyses in the area of time, the layer thicknesses have been adjusted based on the maximum frequency, and in the $h=V_{\mathrm{s}} / 4 f_{\max }$ formula, the analysis was carried out by choosing a layer so that $f_{\max }$ will be between 25 and $50 \mathrm{~Hz}$ (DeepSoil, 2004). The material characteristics of each layer shown in Figs. 8 and 9 were entered and compared with the characteristics of the reference material. Then, when two graphs gave the approximate results, the next step was begun. The earthquake record used in 
Table 1. Selected points and their locations.

\begin{tabular}{lcllcl}
\hline Point & $\begin{array}{c}\text { Section } \\
\text { number }\end{array}$ & Location & Point & $\begin{array}{c}\text { Section } \\
\text { number }\end{array}$ & Location \\
\hline 1A & 1 & Plain & 4A & 4 & Heel of hillside \\
1B & 1 & Top of hillside & 4B & 4 & Heel of hillside \\
1C 1C & 1 & Skirt of hillside & 4C & 4 & Top of hillside \\
1D & 1 & Top of hillside & 4D & 4 & Top of hillside \\
1E & 1 & Skirt of hillside & 4E & 4 & Skirt of hillside \\
1F & 1 & Plain & 4F & 4 & Heel of hillside \\
2A & 2 & Heel of hillside & $4 \mathrm{G}$ & 4 & Top of hillside \\
2B & 2 & Plain & 4H & 4 & Top of hillside \\
2C & 2 & Heel of hillside & 4I & 4 & Top of hillside \\
2D & 2 & Plain & 4J & 4 & Plain \\
2E & 2 & Skirt of hillside & 4K & 4 & Top of hillside \\
2F & 2 & Plain & 5A & 5 & Plain \\
3A & 3 & Heel of hillside & 5B & 5 & Top of hillside \\
3B & 3 & Top of hillside & 5C & 5 & Plain \\
3C & 3 & Plain & 5D & 5 & Skirt of hillside \\
3D & 3 & Top of hillside & 5E & 5 & Heel of hillside \\
3E & 3 & Skirt of hillside & 5F & 5 & Top of hillside \\
3F & 3 & Skirt of hillside & 5G & 5 & Top of hillside \\
3G & 3 & Skirt of hillside & 5H & 5 & Plain \\
3H & 3 & Plain & 5I & 5 & Heel of hillside \\
& & & $5 \mathrm{~J}$ & 5 & Top of hillside \\
& & & $5 \mathrm{~K}$ & 5 & Plain \\
\hline
\end{tabular}

Table 2. Selected $G / G_{\max }$ and damping relations for the formations.

\begin{tabular}{|c|c|c|c|c|}
\hline Formation & $\begin{array}{l}\gamma_{n} \\
\left(\mathrm{kN} \mathrm{m}^{-3}\right)\end{array}$ & Material & Strain-dependent relationships & $\begin{array}{l}V(\min -\max ) \\
\left(\mathrm{m} \mathrm{sn}^{-1}\right)\end{array}$ \\
\hline Fill 1 (Haliç deposits) & 15.5 & Mat 1 & $\begin{array}{l}G / G_{\max }: \text { Vucetic and Dobry }(1991), I_{\mathrm{p}}=25 \% \\
\text { Damping ratio: Vucetic and Dobry }(1991), I_{\mathrm{p}}=25 \%\end{array}$ & $78-182$ \\
\hline Fill 1 (artificial fill) & 18 & Mat 1 & $\begin{array}{l}G / G_{\max }: \text { Vucetic and Dobry }(1991), I_{\mathrm{p}}=25 \% \\
\text { Sönüm oranı: Vucetic and Dobry }(1991), I_{\mathrm{p}}=25 \%\end{array}$ & $204-358$ \\
\hline Fill 2 (alluvial) & 18 & Mat 2 & $\begin{array}{l}G / G_{\max }: \text { Vucetic and Dobry }(1991), I_{\mathrm{p}}=30 \% \\
\text { Sönüm oranı: Vucetic and Dobry }(1991), I_{\mathrm{p}}=30 \%\end{array}$ & $140-340$ \\
\hline Bakırköy clay & 19 & Mat 3 & $\begin{array}{l}G / G_{\max }: \text { Vucetic and Dobry }(1991), I_{\mathrm{p}}=45 \% \\
\text { Sönüm oran1: Vucetic and Dobry }(1991), I_{\mathrm{p}}=45 \%\end{array}$ & $280-385$ \\
\hline $\begin{array}{l}\text { Bakırköy limestone and } \\
\text { Gürpınar limestone }\end{array}$ & 24 & Mat 4 & $\begin{array}{l}\text { Attenuation of rock average and damping in rock, } \\
\text { Idriss (1990) }\end{array}$ & $314-473$ \\
\hline Gürpınar clay & 20 & Mat 5 & $\begin{array}{l}G / G_{\max }: \text { Vucetic and Dobry }(1991), I_{\mathrm{p}}=40 \% \\
\text { Damping ratio: Vucetic and Dobry }(1991), I_{\mathrm{p}}=40 \%\end{array}$ & $101-443$ \\
\hline $\begin{array}{l}\text { Çukurçeşme and } \\
\text { Gürpınar sand }\end{array}$ & 20 & Mat 6 & $\begin{array}{l}G / G_{\max }: \text { Seed and Idriss }(1970), \text { upper range } \\
\text { Damping ratio: Idriss }(1990)\end{array}$ & $119-473$ \\
\hline $\begin{array}{l}\text { Gürpınar base } \\
\text { (sandy gravel) }\end{array}$ & 21 & Mat 7 & $\begin{array}{l}G / G_{\max }: \text { Seed and Idriss (1970), upper range } \\
\text { Damping ratio: Seed and Idriss (1970), average }\end{array}$ & $222-473$ \\
\hline Trakya limestone (bedrock) & 25 & - & Idriss (1990) & 700 \\
\hline
\end{tabular}

${ }^{*} V_{\min }$ is a value at the upper levels of the layer and $V_{\max }$ is the value at the lower levels of the layer. 


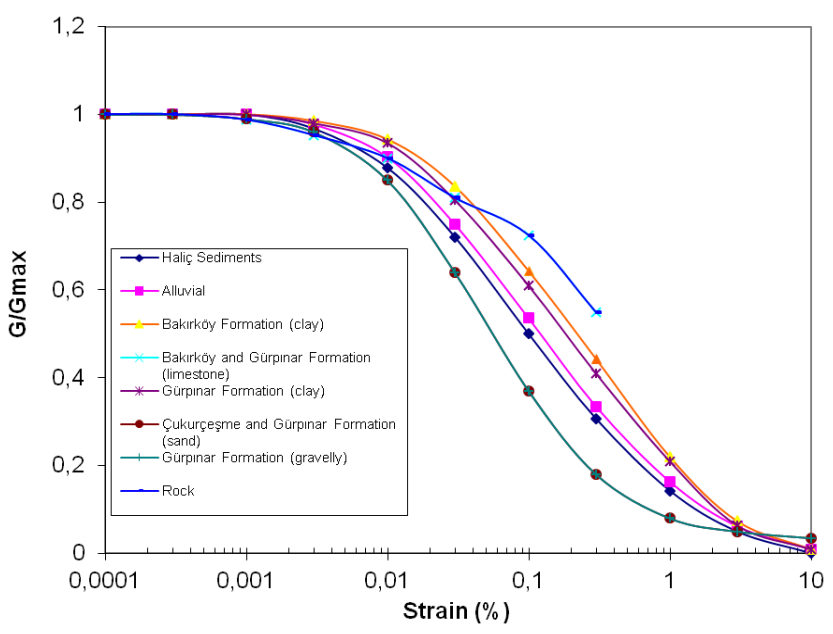

Figure 8. $G / G_{\max }$ and shear strain relationships for all formations.

the next stage was produced by the TARSCHTS (Papageorgiou et al., 2000) program in accordance with the NEHRP acceleration behaviour spectrum based on the spectral acceleration value that would arise in the bedrock artificially. In the next and final stage where dominant frequencies/modes were determined for the nonlinear analysis, the graphs were compared in order to ensure that the analysis in the field of frequency was in accordance with the field of time. In the case where the values in the graph were not close to each other, the 1 st and 2 nd mode values were changed and the transactions were repeated, and alignment was achieved between the two graphs. As specified in the manual version of the Deepsoil program, the concordant graphs of values 1 and 8 give "Default" for the 1st and 2nd modes provided in most of the analyses, and the 1st and 2nd mode values found in this way were substituted in Eq. (1), and Rayleigh $\alpha$ and Rayleigh $\beta$ values were calculated.

$\alpha=2 \xi \frac{w_{i} w_{j}}{w i w_{j}} \quad \beta=2 \xi \frac{1}{w_{i}+w_{j}}$

Here, $\xi$ represents the equivalent damping ratio, and $w_{i}$ and $w_{j}$ represent the angular frequency values in the $i$ and $j$ modes. The results can be obtained as graphs for each layer including the acceleration time, stress time, deformation time, stress deformation, amplitude frequency, and the peak spectral acceleration period.

\subsection{Two-dimensional analysis}

One-dimensional ground response analysis methods are quite useful in flat or slightly inclined surfaces close to a material border. There are many cases of this kind in practice and one-dimensional analyses are widespread in geotechnical earthquake engineering practices. However, one-dimensional wave propagation assumption is not fit for purposes in many other problems encountered in practice. Therefore, two- or maybe three-dimensional analyses are

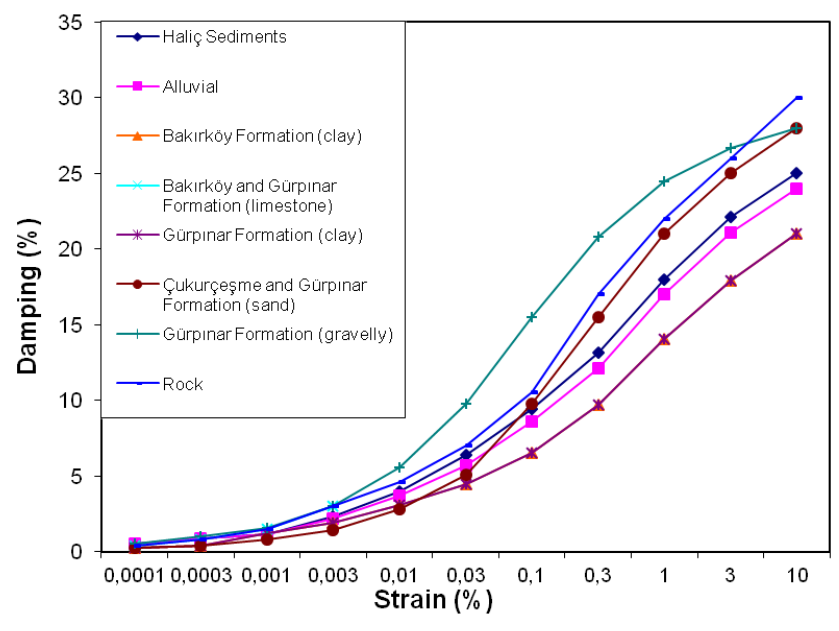

Figure 9. Damping ratio and shear strain relationships for all formations.

needed for all cases that involve rigid or embedded heavy structures or walls and tunnels on inclined or irregular surfaces. Problems in which one dimension is greater than the others can be mostly handled as a two-dimensional planar unit deformation problem. Two-dimensional analyses can be undertaken using a finite element method which finds approximate results for mathematical problems encountered in many branches of engineering. This method is used in areas of ground-structure interaction, consolidation, stress deformation, loading, bearing capacity, flow net and ground dynamics in civil engineering and in other cases of material variety.

In this study, the Plaxis 8.2 version software in conjunction with the finite element method in two-dimensional analyses was used. The version was developed for the applications of geotechnical engineering. In the analyses, problems are analysed in a static manner and two-dimensionally under axial symmetric geometrical conditions. In the program, the stress-deformation behaviour of the material is modelled with nonlinear solution techniques. In this model, the Poisson ratio $(v)$, cohesion $(c)$, internal friction angle $(\varphi)$, expansion angle $(\psi)$, dry and natural unit volume weights of the ground $(\gamma k$ and $\gamma n)$, horizontal and vertical permeability coefficients $(\mathrm{kv}$ and $\mathrm{kh})$ and shear wave speed $\left(V_{\mathrm{s}}\right)$ are entered into the program. The elasticity modulus and shear modulus are automatically calculated by the program using these values. After defining the material parameters, the stage of forming a finite element net is started.

\subsubsection{Material properties used in the analysis}

The Plaxis program is capable of working with five different material models at the same time, including linear elastic (LE), Mohr-Coulomb (MC), jointed rock (JR), soft soil (SS), soft soil creep (SSC) and hardening soil (HS) in order to determine the ground properties. The Trakya formation in 
Table 3. The material parameters in used Plaxis for all formations.

\begin{tabular}{|c|c|c|c|c|c|c|c|c|c|}
\hline Formations & Material model & $\begin{array}{l}\gamma_{\text {dry }} \\
\left(\mathrm{kN} \mathrm{m}^{-3}\right)\end{array}$ & $\begin{array}{l}\gamma_{\text {saturated }} \\
\left(\mathrm{kN} \mathrm{m}^{-3}\right)\end{array}$ & $\begin{array}{c}c \\
\left(\mathrm{kN} \mathrm{m}^{-2}\right)\end{array}$ & $\begin{array}{c}\varphi \\
\left(^{\circ}\right)\end{array}$ & $\begin{array}{c}E_{50}^{\mathrm{ref}} \\
(\mathrm{kPa})\end{array}$ & $\begin{array}{c}E_{\mathrm{ur}}^{\mathrm{ref}} \\
(\mathrm{kPa})\end{array}$ & $\begin{array}{c}E^{\mathrm{ref}} \\
(\mathrm{kPa})\end{array}$ & $\begin{array}{c}V_{\mathrm{s}}^{*} \\
\left(\mathrm{~m} \mathrm{sn}^{-1}\right)\end{array}$ \\
\hline Artificial fill & Hardening soil & 18 & 19 & 1 & 25 & $1.126 \times 10^{-5}$ & $3.885 \mathrm{E} \times 10^{-5}$ & - & - \\
\hline Haliç sediments & Soft soil & 12 & 16.5 & 1 & 14 & - & - & - & - \\
\hline Alluvial fill & Mohr-Coulomb & 13.3 & 18 & 1 & 25 & - & - & $2.349 \times 10^{-5}$ & 258 \\
\hline Bakırköy clay & Hardening soil & 21 & 22 & 12 & 25 & $9.257 \times 10^{-5}$ & $3.124 \times 10^{-6}$ & - & - \\
\hline Bakırköy and Gürpınar limestone & Hardening soil & 21 & 22 & 12 & 25 & $9.257 \times 10^{-5}$ & $3.124 \times 10^{-6}$ & - & - \\
\hline Gürpınar clay & Hardening soil & 20 & 21 & 1 & 25 & $7.052 \times 10^{-5}$ & $2.080 \times 10^{-6}$ & - & - \\
\hline Gürpınar base & Hardening soil & 21 & 21 & 1 & 35 & $6.022 \times 10^{-5}$ & $1.298 \times 10^{-6}$ & - & - \\
\hline Gürpınar and Çukurçeşme sand & Mohr-Coulomb & 19 & 20 & 1 & 30 & - & - & $6.14 \times 10^{-5}$ & 349 \\
\hline Bedrock & Linear elastic & 26 & 28 & 1 & 36 & $9.80 \times 10^{-5}$ & $2.940 \times 10^{-6}$ & $3.12 \times 10^{-6}$ & 700 \\
\hline
\end{tabular}

this study is bedrock defined with the linear elastic material model, while the estuary coastal sediments were defined with the soft soil model. Alluvial, Çukurçeşme and Gürpınar formations were defined with the Mohr-Coulomb model and all the other formations were defined with the hardening soil material model. The other values belonging to the formations entered into the program are shown in Table 3.

The $\alpha$ and $\beta$ damping parameters were obtained from Eq. (1) at the points where the analyses were to be made according to the angular frequency values of $\omega_{1}$ and $\omega_{2}$, which were obtained from the Rayleigh damping curve produced from nonlinear analysis in the Deepsoil program (Table 4).

\subsubsection{Earthquake motion input file used in the analysis}

The earthquake motion amplitudes entered into the twodimensional dynamic analysis at the level of bedrock were synthetically produced with the TARSCHTS (Papageorgiou et al., 2000) program. The peak and spectral acceleration values of the bedrock used in the program were produced probabilistically using the source zoning carried out by Bosphorus University (Ince, 2012).

\section{Analysis results and evaluations}

One- and two-dimensional analyses were made at the points where the field topography changed and on the hillside, the heel of the hillside, hilly plains and coastal plains where the results were expected to differentiate and at the same time at the points where different formations are layered based on depth. The points chosen, their formation information and their topographical positions are shown in Table 1. The results of the analysis results were obtained as a peak acceleration change in the section surfaces and the section depth and also as spectral acceleration period graphs for the selected points.

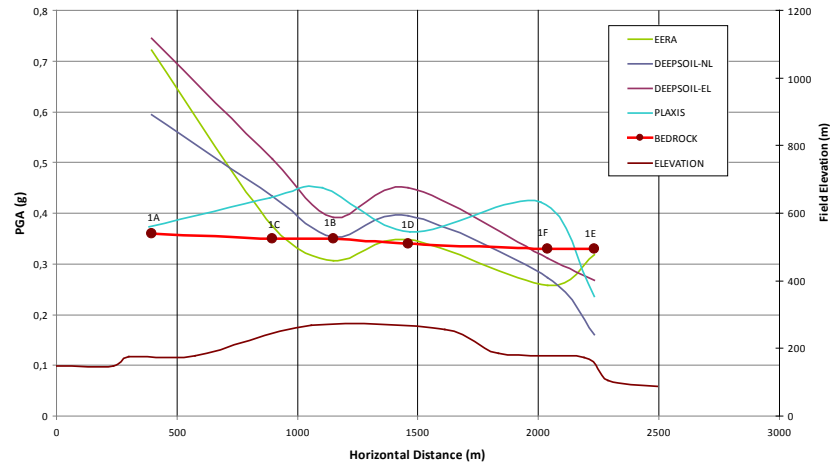

Figure 10. Change in the peak ground acceleration on the surface for the $1-1^{\prime}$ section.

\subsection{Change in peak ground acceleration values on the surface}

In one-dimensional analyses the earthquake wave progresses only vertically upwards from the bedrock. However, it progresses in two dimensions in the direction of earthquake wave propagation from left to right. In this case, as the effect of the topographical change on the surface acceleration can be observed in the two-dimensional analysis, the effect of layer thicknesses appears in one dimension. In this study, the results of one- and two-dimensional analyses were evaluated with and within each other and the correlation between them was obtained.

For the one-dimensional analysis, the EERA and DEEPSOIL (equivalent linear - EL - and nonlinear - NL) programs were used and the PLAXIS 8.2 finite element program was used for the two-dimensional analyses. For all the sections, the change in the maximum surface acceleration on the ground surface is shown together with the change in peak acceleration value belonging to the bedrock as shown in Figs. 10 to 14.

The results of the one-dimensional analysis show a descending tendency between points $1 \mathrm{~A}$ and $1 \mathrm{C}$, where the fill layer that was $14 \mathrm{~m}$ at the beginning gave way to a thick clay layer reaching $40 \mathrm{~m}$. In the two-dimensional analysis, an increase in the acceleration value was observed upwards from 
Table 4. $\alpha$ and $\beta$ values at selected points for all sections.

\begin{tabular}{|c|c|c|c|c|}
\hline Point & $\begin{array}{l}\text { Section } \\
\text { number }\end{array}$ & $\omega_{1}$ and $\omega_{2}$ & $\alpha$ & $\beta$ \\
\hline $1 \mathrm{~A}$ & 1 & $1-3$ & 0.075 & 0.025 \\
\hline 1B & 1 & $1-8$ & 0.089 & 0.0111 \\
\hline $1 \mathrm{C}$ & 1 & $1-5$ & 0.0833 & 0.0167 \\
\hline $1 \mathrm{D}$ & 1 & $1-5$ & 0.0833 & 0.0167 \\
\hline $1 \mathrm{E}$ & 1 & $1-5$ & 0.0833 & 0.0167 \\
\hline $1 \mathrm{~F}$ & 1 & $1-3$ & 0.075 & 0.025 \\
\hline $2 \mathrm{~A}$ & 2 & $1-5$ & 0.0833 & 0.0167 \\
\hline $2 B$ & 2 & $1-5$ & 0.0833 & 0.0167 \\
\hline $2 \mathrm{C}$ & 2 & $1-8$ & 0.089 & 0.0111 \\
\hline $2 \mathrm{D}$ & 2 & $1-5$ & 0.0833 & 0.0167 \\
\hline $2 \mathrm{E}$ & 2 & $1-5$ & 0.0833 & 0.0167 \\
\hline $2 \mathrm{~F}$ & 2 & $1-3$ & 0.075 & 0.025 \\
\hline $3 \mathrm{~A}$ & 3 & $1-8$ & 0.0890 & 0.0111 \\
\hline $3 B$ & 3 & $1-8$ & 0.0890 & 0.0111 \\
\hline $3 C$ & 3 & $1-8$ & 0.0890 & 0.0111 \\
\hline $3 \mathrm{D}$ & 3 & $1-8$ & 0.0890 & 0.0111 \\
\hline $3 \mathrm{E}$ & 3 & $1-5$ & 0.0833 & 0.0167 \\
\hline $3 \mathrm{~F}$ & 3 & $1-5$ & 0.0833 & 0.0167 \\
\hline $3 \mathrm{G}$ & 3 & $1-8$ & 0.0890 & 0.0111 \\
\hline $3 \mathrm{H}$ & 3 & $1-8$ & 0.0890 & 0.0111 \\
\hline $4 \mathrm{~A}$ & 4 & $1-8$ & 0.0890 & 0.0111 \\
\hline $4 \mathrm{~B}$ & 4 & $1-8$ & 0.0890 & 0.0111 \\
\hline $4 \mathrm{C}$ & 4 & $1-8$ & 0.0890 & 0.0111 \\
\hline $4 \mathrm{D}$ & 4 & $1-8$ & 0.0890 & 0.0111 \\
\hline $4 \mathrm{E}$ & 4 & $1-8$ & 0.0890 & 0.0111 \\
\hline $4 \mathrm{~F}$ & 4 & $1-3$ & 0.075 & 0.025 \\
\hline $4 \mathrm{G}$ & 4 & $1-3$ & 0.075 & 0.025 \\
\hline $4 \mathrm{H}$ & 4 & $1-8$ & 0.0890 & 0.0111 \\
\hline $4 \mathrm{I}$ & 4 & $1-8$ & 0.0890 & 0.0111 \\
\hline $4 \mathrm{~J}$ & 4 & $1-8$ & 0.0890 & 0.0111 \\
\hline $4 \mathrm{~K}$ & 4 & $1-3$ & 0.075 & 0.025 \\
\hline $5 \mathrm{~A}$ & 5 & $1-8$ & 0.0890 & 0.0111 \\
\hline $5 B$ & 5 & $1-8$ & 0.0890 & 0.0111 \\
\hline $5 \mathrm{C}$ & 5 & $1-8$ & 0.0890 & 0.0111 \\
\hline $5 \mathrm{D}$ & 5 & $1-8$ & 0.0890 & 0.0111 \\
\hline $5 \mathrm{E}$ & 5 & $1-8$ & 0.0890 & 0.0111 \\
\hline $5 \mathrm{~F}$ & 5 & $1-5$ & 0.0833 & 0.0167 \\
\hline $5 \mathrm{G}$ & 5 & $1-8$ & 0.0890 & 0.0111 \\
\hline $5 \mathrm{H}$ & 5 & $1-5$ & 0.0833 & 0.0167 \\
\hline $5 \mathrm{I}$ & 5 & $1-8$ & 0.0890 & 0.0111 \\
\hline $5 \mathrm{~J}$ & 5 & $1-8$ & 0.0890 & 0.0111 \\
\hline $5 \mathrm{~K}$ & 5 & $1-8$ & 0.0890 & 0.0111 \\
\hline
\end{tabular}

the slope. It could be thought here that the changing topography appeared in the two-dimensional analysis.

The decrease in the clay layer of about $10 \mathrm{~m}$ between points 1B and 1D (between two peak points) gave way to an increase in the fill layer of almost the same amount. In this case, while the acceleration value increased in the one-dimensional analyses, on the contrary it was observed that the acceleration value decreased in the two-dimensional analyses.

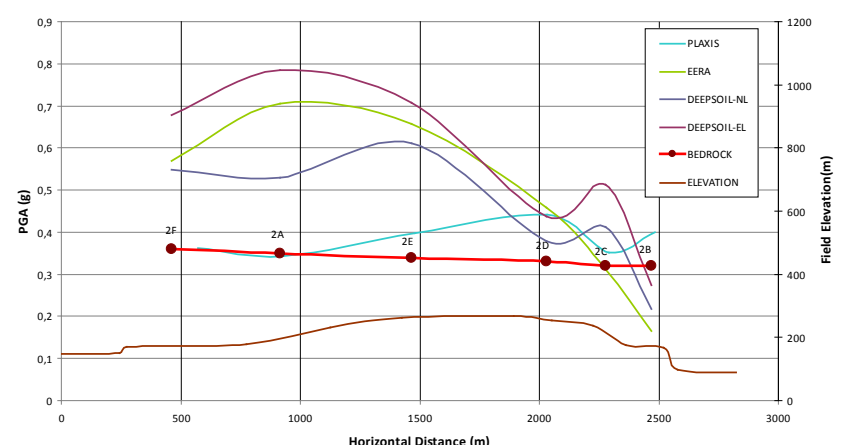

Figure 11. Change in the peak ground acceleration on the surface for the $2-2^{\prime}$ section.

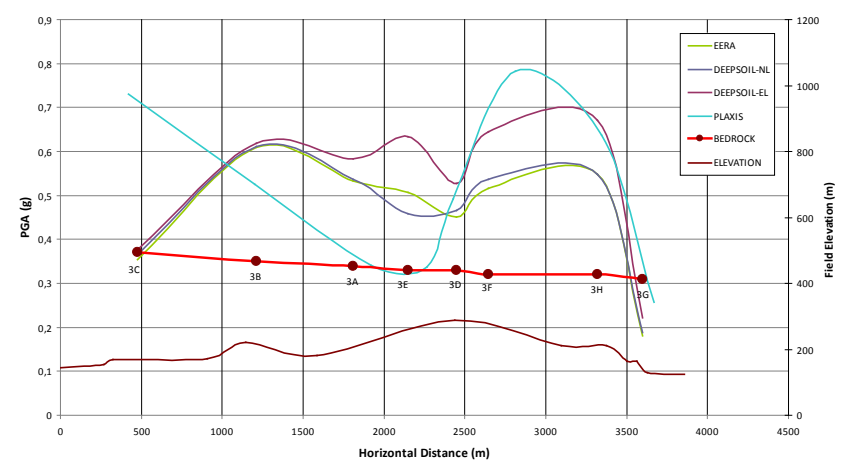

Figure 12. Change in the peak ground acceleration on the surface for the $3-3^{\prime}$ section.

It is seen that the clay layer between the 1D peak point and the IF point at sea level ends with faulting and the bedrock approaches to the surface. The thickness of the fill layer first increases, then decreases when the slope ends and bedrock surfaces and again increases towards the coast, reaching a thickness of $45 \mathrm{~m}$. In this case, it is seen that the acceleration decreases in the one-dimensional analyses. The parameter effective in this situation could be the ending of the clay layer and the surfacing of the bedrock. Considering the two-dimensional analyses, a totally opposite behaviour is observed, thus the acceleration values increase. It is observed that the topographical conditions changing from top down create a difference in the results of the two analyses.

In Sect. 2 the thicknesses of soils on the bedrock are less than the other sections, as in the north-west and south-east directions. In the section, the decreasing fill layer thickness gives way to clayey levels between the $2 \mathrm{~F}$ and $2 \mathrm{~A}$ points. As this change gives rise to an increase in the acceleration value in the one-dimensional analyses, the acceleration value continues as equal to the bedrock value and without changing in the two-dimensional analyses. The thickness of the clayey layer between the 2A and 2D points slightly increases and then decreases, and the Bakırköy limestone is located at the hilly levels. Considering the results of the one-dimensional analysis, it is seen that the acceleration value decreases. The 


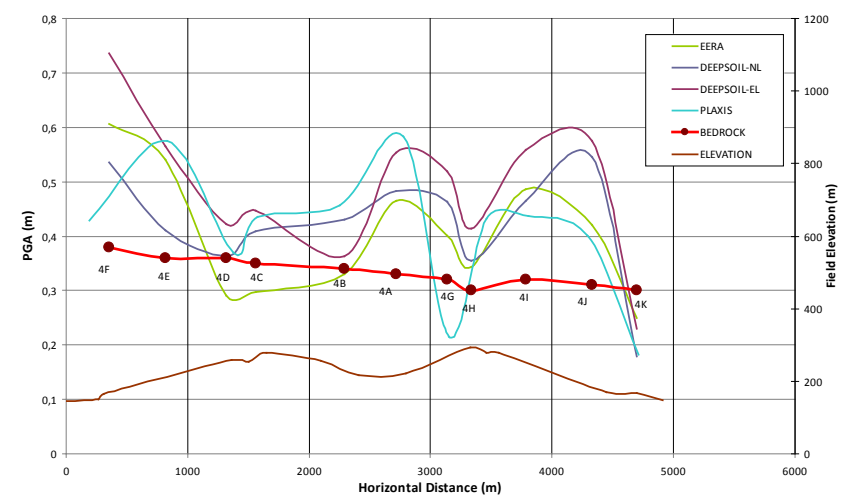

Figure 13. Change in the peak ground acceleration on the surface for the $4-4^{\prime}$ section.

reason for this is thought to be that the limestone levels show the properties of a fractured rock. From the $2 \mathrm{~A}$ point that is the beginning of the slope to the $2 \mathrm{D}$ point at hilly levels, an increase is seen in the two-dimensional analysis, which is contrary to the results of the one-dimensional analysis. The values of DEEPSOIL-EL and DEEPSOIL-NL increase, the EERA result decreases between the $2 \mathrm{D}$ and $2 \mathrm{C}$ points where the clayey levels end and gives way only to the fill with a thickness of $4 \mathrm{~m}$ in the two-dimensional analysis, and the acceleration value decreases.

In the section there are two peaks and the results of the one- and two-dimensional analyses exhibit a behaviour that is totally opposite at the beginning of the graph. In the onedimensional analyses, the surface acceleration value of the $3 \mathrm{C}$ point is equal to the bedrock acceleration value, that is, the fill layer with a thickness of $25 \mathrm{~m}$ does not cause any change in the acceleration. It is observed that the fill layer with a thickness of $25 \mathrm{~m}$ gradually decreases from right to left and gives way to a clayey layer with a thickness of $30 \mathrm{~m}$ at the 3B peak point. In this case, it is seen that the acceleration values increase in the one-dimensional analyses. With the decrease in the thickness of the fill layer at the $3 \mathrm{C}$ point, the acceleration value increases and the clayey layer reaches a thickness of $30 \mathrm{~m}$; as a result, the peak values are achieved.

The thickness of the clayey layer between the $3 \mathrm{~B}$ and $3 \mathrm{D}$ points decreases until the valley and then increases again in the second hilly place, but the effect of these changes is observed as a decrease in the acceleration graph, while the clayey layer with a thickness of $5 \mathrm{~m}$ between the 3D and $3 \mathrm{H}$ points, which are the top levels of the second hill, gradually decreases from the top down and gives way to a fill layer of $6 \mathrm{~m}$ after ending with faulting. This change gives rise to an increase in the acceleration values. The fill layer between the $3 \mathrm{H}$ and $3 \mathrm{G}$ points ends and gives way to estuary sediments reaching a thickness of $45 \mathrm{~m}$ in the sea. In this case, it is seen that the acceleration values rapidly reduce and even fall below the acceleration value of the bedrock. It is observed that the estuary sediments are located at the sea bottom in the

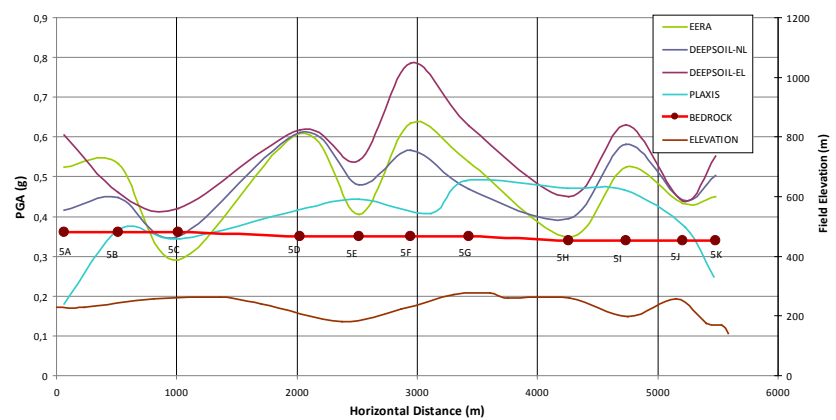

Figure 14. Change in the peak ground acceleration on the surface for the $5-5^{\prime}$ section.

form of slurry that has the effect of decreasing the earthquake acceleration.

On the other hand, examining the two-dimensional acceleration graph shows that the acceleration value decreases until the $3 \mathrm{E}$ point located on the second hilly area and exhibits a behaviour almost consistent with the one-dimensional analysis results after this point.

In Sect. 4, it is observed that the results of the one- and two-dimensional analyses are more compatible in comparison to the other sections. In the two-dimensional analysis, the beginning of the graph is just the opposite of the sections, but is in accordance with the one-dimensional analyses. This difference that occurs at the beginning results from the calculations of the Plaxis program under the initial limit conditions. The values between the $4 \mathrm{E}$ and $4 \mathrm{D}$ points where the field topographical incline increases from left to right sharply declines in each of the three graphs. It is thought that the parameter effective in the one-dimensional analysis is the Bakırköy limestone located at the upper levels of the section and gradually thickening. Between points $4 \mathrm{D}$ and $4 \mathrm{C}$ the surface topography and the thicknesses of Bakırköy limestone levels change and their effect is again observable in the results of the three analyses. However, the EERA results fall below the bedrock peak acceleration values until the $4 \mathrm{~B}$ point, that is, the end of the Bakirköy formation. Between points $4 \mathrm{~B}$ and $4 \mathrm{~A}$ where the old stream bed is situated at the bottom of the valley and the alluvial layer is located, the values increase and reach a peak at the $4 \mathrm{~A}$ point. After this point, while the wave moves upwards from the slope, the acceleration value decreases in all analyses and reaches the lowest levels on the hill. In the one- and two-dimensional analyses, different parameters can be said to have an effect on this change. The clayey levels which are quite thick might cause the acceleration to decrease in the one-dimensional analyses (from 20 to $50 \mathrm{~m}$ ). On the other hand, such a decrease is observed in all the sections in the two-dimensional analyses when going upwards from the slope. From point $4 \mathrm{H}$ at the peak of the section down to the 4I point, the acceleration value increases again in the one-dimensional analyses and the result of the two-dimensional analyses also increases, 
while the clayey layer decreases. The surface incline continues downwards from points $4 \mathrm{I}$ to $4 \mathrm{~J}$; at the same time, the bedding changes and clayey levels end and give way to the fill layer. The thickness of the fill layer gradually increases towards the coast. In this case, the values of the surface acceleration reach peak levels. At the $4 \mathrm{~K}$ point where the estuary coastal sediments are situated, the values fall to the lowest levels. It is observed that the estuary coastal sediments located in the sea in the form of slurry effectively lower the acceleration value.

In Sect. 5, the initial values of Plaxis begin differently due to the limit conditions as in the other sections. It is observed that the thickness of the clayey layer rises to $73 \mathrm{~m}$ and the acceleration value decreases until the $5 \mathrm{C}$ point where the thickness of the Bakırköy limestone increases. From the $5 \mathrm{C}$ point on the hill down to the 5D point, which is located downwards from the slope, the thickness of the clayey layer decreases and falls to $20 \mathrm{~m}$. The Bakırköy limestone located on the clayey layer gradually decreases and disappears. In this case, the acceleration value in the one-dimensional analyses increases. The bedrock between the $5 \mathrm{D}$ and $5 \mathrm{E}$ points at the bottom of the valley almost surfaces, and only a fill layer of $5 \mathrm{~m}$ remains on the bedrock. In this case, the acceleration value in the one-dimensional analyses decreases; however, on the contrary, the acceleration value in the two-dimensional analysis increases. The influential aspect here is thought to be the second dimension effect which occurs downwards from the hillside. Between the 5E point where the bedrock and the fill of $5 \mathrm{~m}$ are located upwards from the slope and the $5 \mathrm{~F}$ point where a clayey layer of $5 \mathrm{~m}$ and a fill of $5 \mathrm{~m}$ are placed on the bedrock, the acceleration value increases in the one-dimensional analyses and reaches a peak at 5F. On the contrary, in the two-dimensional analyses the acceleration value decreases. The field topography and changes upwards from the slope can be influential in the two-dimensional analyses. The acceleration value falls to the lowest values between the $5 \mathrm{~F}$ and $5 \mathrm{H}$ points in the one-dimensional analyses. The clayey layer that thickens (from 25 to $38 \mathrm{~m}$ ) and the limestone levels that are partly placed are thought to be influential here. Another important point is that the clayey levels up to 20-25 $\mathrm{m}$ increase the acceleration but decrease the acceleration after $25 \mathrm{~m}$ in the one-dimensional analyses. In the two-dimensional analyses, the acceleration value increases between the $5 \mathrm{~F}$ and $5 \mathrm{G}$ points upwards from the slope and remains stable on the hill between the $5 \mathrm{G}$ and $5 \mathrm{H}$ points.

In the case where the clayey levels between $5 \mathrm{H}$ and $5 \mathrm{I}$ fall from 35 to $18 \mathrm{~m}$, it is observed that the acceleration value increases in the one-dimensional analyses and reaches the peak level at 5I. However, a great change is not seen in the twodimensional analyses moving downwards from the slope.

The thickness of the $15 \mathrm{~m}$ fill layer decreases to $5 \mathrm{~m}$ between points $5 \mathrm{I}$ and $5 \mathrm{~J}$ (the bottom and peak points of the valley), in which case the acceleration value gradually decreases in the one-dimensional analyses. In the two-dimensional analyses, a decrease is seen in the acceleration going downwards from the slope.

\subsection{Change in peak ground acceleration values by depth}

The results of the analyses made at the points selected along the borders of the changing layer are shown for all sections together with the one and two-dimensional analysis results in Figs. 15 to 19 in order to examine the change in the layer border.

All the analysis results are consistent in terms of the change-depth graph of the $1 \mathrm{D}$ point. The acceleration value rapidly increases from 0.2 to 0.45 especially after $20 \mathrm{~m}$, where the artificial fill layer starts. As the results at the $1 \mathrm{~B}$ and $1 \mathrm{~F}$ points are higher in the two-dimensional analyses, the lowest values are obtained from the EERA analysis in the one-dimensional analyses.

When examining the acceleration spectrum graph strong spectral reactions ranging between 0.77 and $1.04 \mathrm{~g}$ at $1 \mathrm{~F}, 0.97$ and $1.35 \mathrm{~g}$ at $1 \mathrm{~B}$ and 1.05 and $1.3 \mathrm{~g}$ at $1 \mathrm{D}$ are observed at each of three points in a short time interval of $0.10-0.40 \mathrm{~s}$. The results obtained by PLAXIS are quite different and larger values were obtained compared with one-dimensional analyses.

While the results of the two-dimensional analysis change from 0.19 to 0.27 at point $2 \mathrm{~A}$, that is at the beginning of the slope, they rapidly increase to the values of 0.53 to 0.78 in the final $20 \mathrm{~m}$ where the bedrock disappears and the clayey layer appears. The prevailing interval of this point on the surface is $0.17-0.41 \mathrm{~s}$ and the peak spectral acceleration values change from 2.02 to 2.19 in a short time interval. At the $2 \mathrm{C}$ point where the bedrock is quite close to the surface, the results of all the analyses are in accordance and increase after $20 \mathrm{~m}$. The prevailing time interval of the spectrum changes from 0.05 to 0.34 as the peak spectral acceleration value remains at 0.05 and instantly increases from 0.78 to 1.7 for the analyses, and then the range is $0.6-0.8$. The results obtained by PLAXIS are similar at point $2 \mathrm{~A}$ but quite different at point $2 \mathrm{C}$.

At the 3B point which consists of a clayey layer of about $30 \mathrm{~m}$ and a fill layer of $5 \mathrm{~m}$, the results of one-dimensional analyses continue in accordance with each other along the depth and rapidly increase from 0.27 to 0.6 at the final $20 \mathrm{~m}$. The prevailing period value is from 0.11 to 0.49 and the peak spectral acceleration values range from 1.83 to 2.35 . The value of two-dimensional analysis rises from 0.25 to 0.5 between 40 and $70 \mathrm{~m}$ and then remains stable throughout the clayey layer.

At the $3 \mathrm{H}$ point where the bedrock and an artificial fill layer of $3 \mathrm{~m}$ are situated, the results of the two-dimensional analyses are greater than those of the one-dimensional analysis but give the same values as the one-dimensional analysis with the initiation of the fill layer. The one-dimensional analysis results continue very close to each other and rapidly increase from $0.22-0.29$ to $0.54-0.67$ after the final $10 \mathrm{~m}$. The peak spectral acceleration values of $1.87-2.37 \mathrm{~g}$ are achieved 

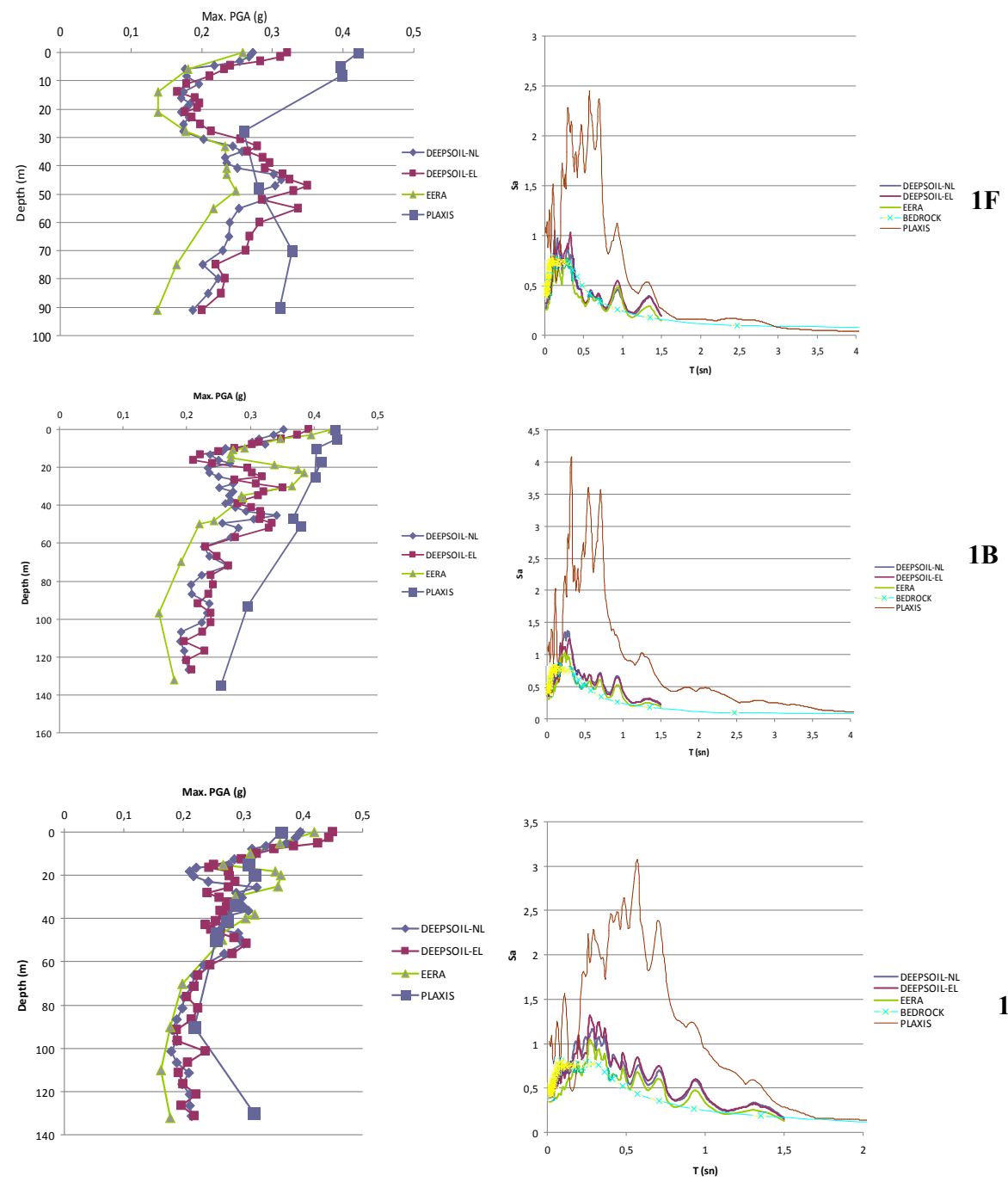

1D

Figure 15. 1-1' section; maximum acceleration depth and spectral acceleration period graph for the selected points.

in a short time interval of $0.20-0.30 \mathrm{~s}$. Three times the difference between the results of the one- and two-dimensional analyses is observed.

In the depth acceleration graph of the 4E point where the fill layer has a thickness of $65 \mathrm{~m}$, the Bakırköy limestone of $3 \mathrm{~m}$ and a fill layer of $6 \mathrm{~m}$ on the top, the results of the onedimensional analyses continue in accordance with each other and rapidly increase from $0.23-0.28$ to $0.41-0.57$; especially after the final $10 \mathrm{~m}$ the two-dimensional analysis results give greater values. The peak spectral acceleration increases to values $1.46-1.63$ for $0.15 \mathrm{~s}$ as the prevailing time interval is $0.13-0.37$.

The 4A point situated at the bottom of the valley consists of a clayey layer of $25 \mathrm{~m}$ and a fill layer of $3 \mathrm{~m}$. The results of the one-dimensional analyses are in accordance and increase from 0.25 to 0.33 to a value of 0.55 after the final $10 \mathrm{~m}$. The result of the two-dimensional analysis is greater and discordant compared to that of the one-dimensional analysis and exhibits a zigzag behaviour. It can be seen that there are two prevailing peak points in the spectral acceleration graph. The peak spectral acceleration value changes from 1.28 to 1.52 within $0.25 \mathrm{~s}$.

The $4 \mathrm{H}$ point is situated on a hill which consists of $45 \mathrm{~m}$ clay and $2 \mathrm{~m}$ fill. While the EERA value is lower in the one-dimensional analyses, the acceleration value increases from 0.22 to 0.42 . While the prevailing period changes between 0.06 and 0.29 , the spectral acceleration value changes between 0.8 and 1 . As with other sections, the results of the Plaxis are quite large values.

At the $5 \mathrm{E}$ point at the bottom of the valley, there is bedrock and a fill layer of $5 \mathrm{~m}$ on this bedrock. In the depth analysis, it is seen that the EERA results are lower. While the acceleration does not change greatly where the bedrock is situated, it rapidly increases with the beginning of the fill layer. The results of the two-dimensional analyses do not change. In the spectral acceleration period graph, the results of the Deepsoil 

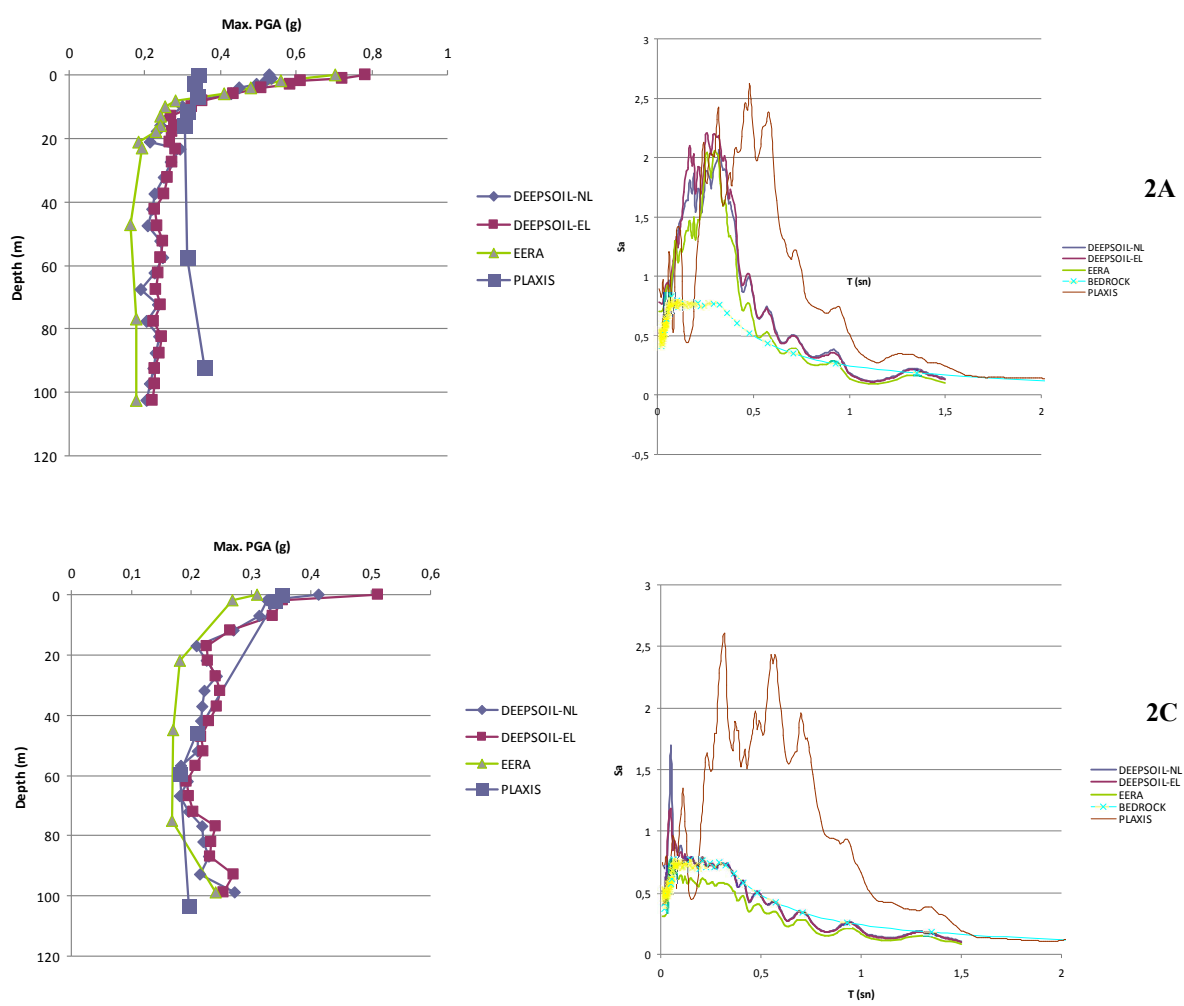

Figure 16. 2-2' section; maximum acceleration depth and spectral acceleration period graph for the selected points.
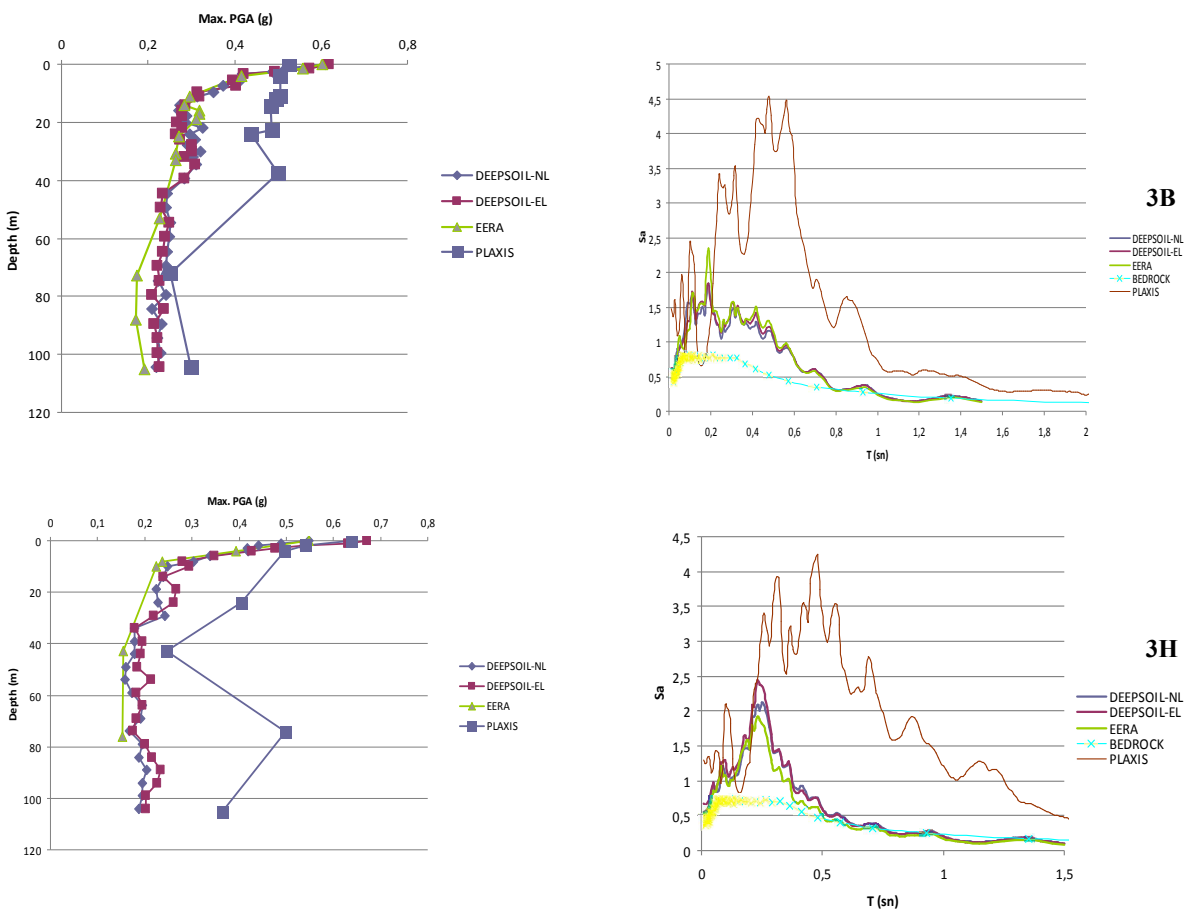

Figure 17. 3-3' section; maximum acceleration depth and spectral acceleration period graph for the selected points. 

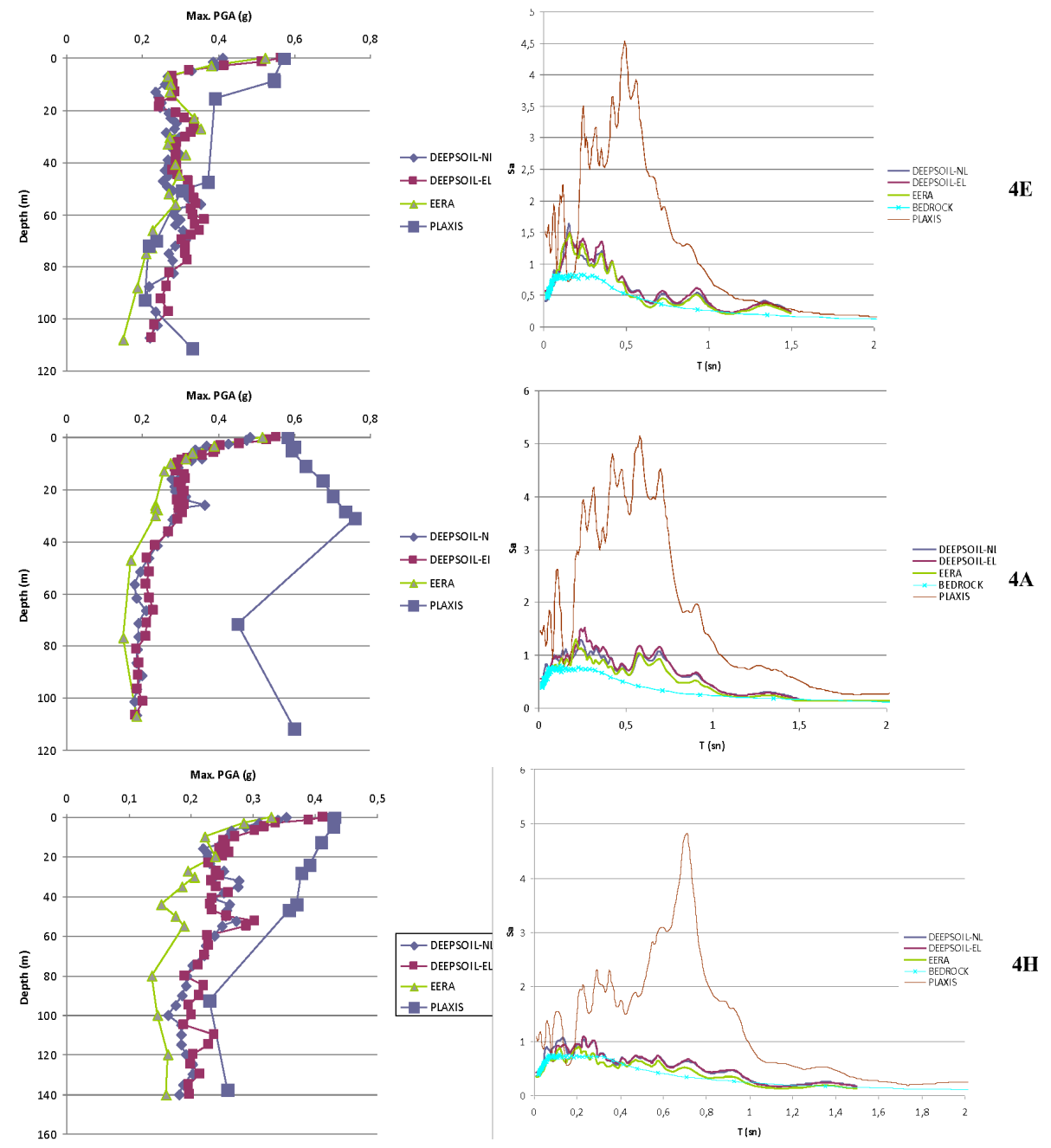

Figure 18. 4-4' section; maximum acceleration depth and spectral acceleration period graph for the selected points.

analysis reach a peak value of 2.5 and the prevailing period is quite narrow. The reason is that the thickness of the fill layer is thin, and as the layer thickness increases, the effect of the earthquake is higher and the period is extended.

The $5 \mathrm{~F}$ point is situated almost in the middle of a slope which consists of a clayey layer of $25 \mathrm{~m}$ and a fill layer of $3 \mathrm{~m}$. It is seen that the acceleration changes by depth much more when compared to the $5 \mathrm{E}$ point. The reason for this could be the thick clayey layer. The result of twodimensional analysis increases from 0.33 to 0.40 from the bedrock to the surface. The spectral acceleration period graph takes the biggest spectral acceleration value between the time interval of $0.14-0.36$ and is seen as the prevailing time interval. It is seen that the thick clayey layer of about $25 \mathrm{~m}$ causes the earthquake force to be more effective and that the repetition period increases as there is no repetition frequency, although the peak value of the fill layer with a thickness of $5 \mathrm{~m}$ at the $5 \mathrm{E}$ point is higher.

\subsection{Effect of surface topography on soil behaviour}

Section $5-5^{\prime}$ was selected in order to examine the effect of surface topography on the analysis results. A simplified model in which the surface and material borders are assumed to be flat was formed (Fig. 20) and the surface acceleration values were obtained from the analyses carried out (Fig. 21).

Figure 21 shows that the acceleration values at the $5 \mathrm{D}$ point that is actually a valley are very close to each other in the one-dimensional analyses and the value is 0.6 , but the results of one-dimensional analyses differ, being 0.58 for the Deepsoil nonlinear and EERA models, while increasing to 0.66 for the Deepsoil equivalent linear analysis. Examining the result of the two-dimensional analysis, this value which was 0.42 increased to 0.57 in the flattened case. The results of the one-dimensional analyses at the $5 \mathrm{E}$ point exhibit similar behaviours and reach the bottom level, but the results of the Deepsoil equivalent linear (EL) and Deepsoil nonlinear (NL) analyses continue to flatten. As 

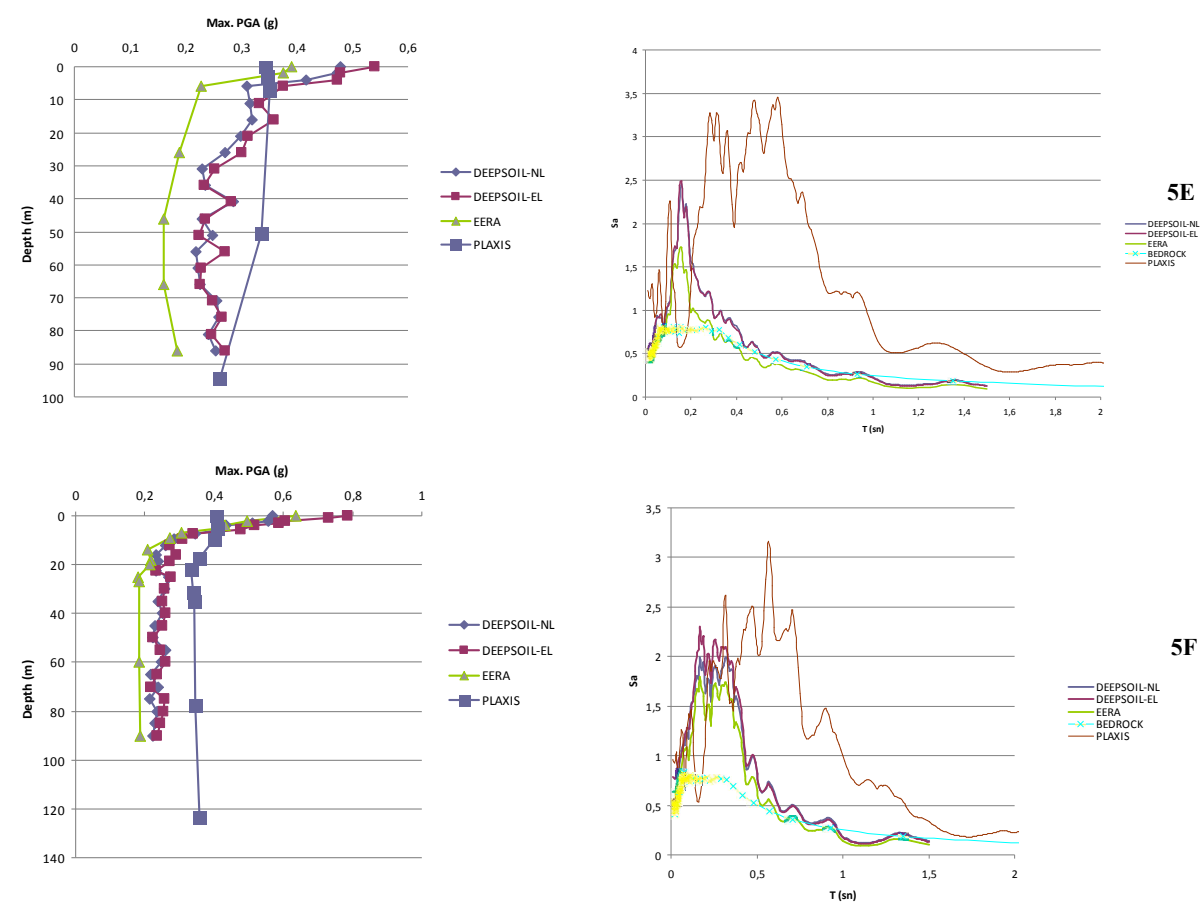

Figure 19. 5-5' section; maximum acceleration depth and spectral acceleration period graph for the selected points.

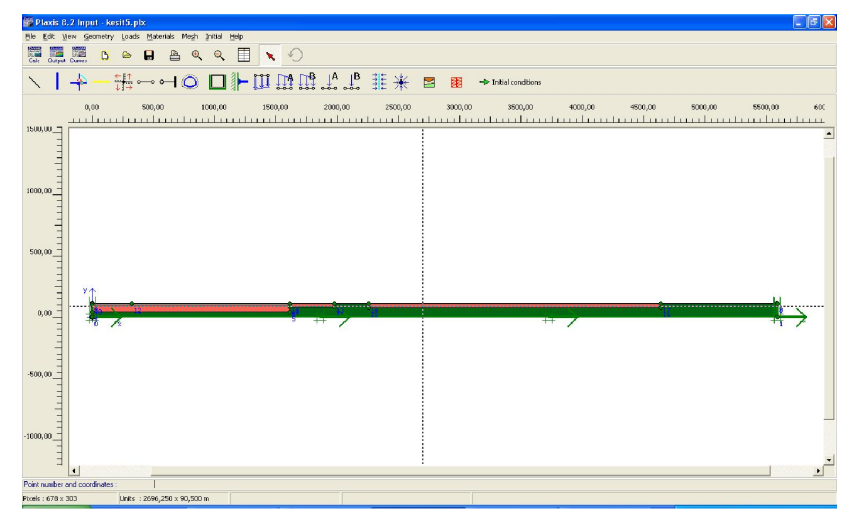

Figure 20. For the 5-5' section, a simplified model in which the surface and material borders are assumed to be flat.

a result of two-dimensional analysis, the value is 0.46 , increasing to 0.69 in the flattened case; thus it can be seen that when the surface flattens, the acceleration value increases. At the $5 \mathrm{G}$ point, as the acceleration value increases from 0.48 to 0.58 in the two-dimensional analysis, the results of one-dimensional analyses make the graphs horizontal and the values range from 0.40 to 0.60 . In the real topography, as the graph of one-dimensional analyses results declines, its value changes from 0.48 to 0.64 . At the $5 \mathrm{H}$ point, as the results of the one-dimensional analyses reach the bottom value, the value changes from 0.37 to 0.47 , and it is 0.48 in the two-dimensional analyses. In the flattened section, the one-dimensional analysis results of the

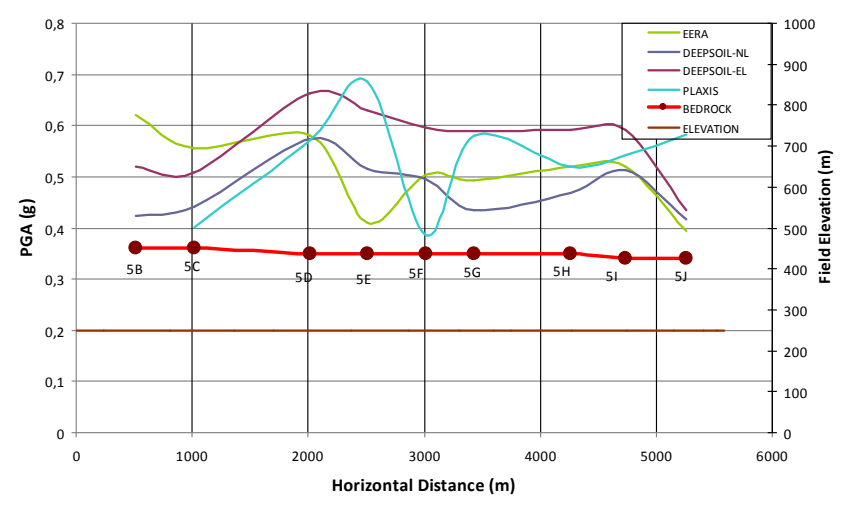

Figure 21. Change in maximum acceleration by depth for five points chosen for the section.

same point are parallel to each other, have an ascending tendency, and their values change from 0.47 to 0.59 . The one-dimensional analysis results reach the peak level at the 5I point at the bottom of the second valley and their values change from 0.53 to 0.63 ; while the value is 0.47 in the twodimensional analyses, they increase to 0.54 in the case of flattening. At the $5 \mathrm{~J}$ point which is the final hilly part, the one-dimensional analysis results give almost the same lowest values and are around 0.44 . When examining these values in the case of flattening, they change from 0.40 to 0.44 in the one-dimensional analysis, and increase to 0.60 in the twodimensional analysis. 
Considering the results, it is observed that the surface topography has an influence on and changes the acceleration value. Moreover, when the field topography becomes flat, the acceleration values can be said to increase in the one and two-dimensional analyses.

Edited by: R. Lasaponara

Reviewed by: G. P. Ganapathy and another anonymous referee

\section{References}

Alım, C.: Comparison of One and Two Dimensional Site Response Analysis results of Dynamic Behaviour of Soil, Master Thesis, Yıldız Technical University, Istanbul, 2006.

Ansal, A. M.: Effects of Geotechnical Factors and Behaviour of Soil Layers During Earthquakes, State-of-the-Art Lecture, Proc. of 10th European Con. on Earthquake Engineering, Wien, Austria, 467-476, 1994.

Ansal, A. M.: Strong Motions and Site Amplification, Theme Lecture, Second International Conference on Earthquake Geotechnical Engineering, Lisbon, Portugal, Vol. 3, Balkema Publishers, Rotterdam, 879-894, 1999.

Ansal, A. M., Yıldırım, H., and Erken, A.: Cyclic Stress-Strain-Pore Pressure Behaviour of Soils, Vol. 2, Proc. Of Int. Symposium on 70 Years of Soil Mechanics, Istanbul, 43-71, 1995.

Assimaki, D. and Jeong, S.: Ground-Motion Observations at Hotel Montana during the $M 7.02010$ Haiti Earthquake: topography or Soil Amplification?, Bull. Seismol. Soc. Am., 103, 2577-2590, 2013.

Bardet, J. P., Ichii, K., and Lin, C. H.: EERA: A Computer Program for Equivalent-Linear Earthquake Response Analyses of Layered soil Deposits, University of Southern California, Los Angeles, 2000.

DeepSoil: Tutorial and User Manual, V2.5, Board of Trustees of University of Illinois at Urbana-Champaign and Youssef Hashash, 2004.

Haşal, M. E.: The effect of Topographical Irregularities on Soil Amplification, Istanbul Technical University, Master Thesis, İstanbul, 2009.
Hough, S. E., Altidor, J. R., Anglade, D., Given, D., Janvier, M. G., Maharrey, J. Z., Meremonte, M., Mildor, B. S., Prepetit, C., and Yong, A.: Localized damage caused by topographic amplification during the 2010 M 7.0 Haiti earthquake, Nat. Geosci., 3, 778-782, 2010.

Idriss, I. M.: Response of soft soil sites during earthquakes, Proceedings of the Symposium to Honor Professor Harry Bolton Seed, Berkeley California, Vol. II, 273-289, 1990.

Iglesias, J.: Seismic Microregionalization of Mexico City after the 1985 Earthquake, Proc. Ninth World Conf. On Earthquake Eng., Vol. 2, Sayfa, 127-132, 1988.

Ince, G. Ç.: Probabilistic seismic hazard assessment of the historical peninsula of Istanbul, Nat. Hazards Earth Syst. Sci., 12, 34833493, doi:10.5194/nhess-12-3483-2012, 2012.

İnce, G. Ç., Özaydın, K., Yıldırım, M., and Özener, P.: Geological and Geotechnical Structure of Historical Peninsula (Istanbul) and Its Seismic Microzonation, Bull. Eng. Geol. Environ., 67, 41-51, doi:10.1007/s10064-007-0099-9, 2008.

Kale, P.: Investigation of the effect of local soil condition with one and two dimensional analyses, Y1ldı Technical University, Ms. Thesis, İstanbul, 2008.

Papageorgiou, A., Halldorsson, B., and Dong, G.: TARSCHTS: Target acceleration spectra compatible time histories, Dept. of Civil, Structural and Environmental Engrg., University of Buffalo, NY, 2000.

Plaxis 8.2: Finite Element Program, Dynamics Manual, Delft University, Delft, the Netherlands, 2002.

Schnabel, P. B., Lysmer, J., and Seed, H. B.: SHAKE: a Computer Program for Earthquake Response Analysis of Horizontally Layered Sites, Report EERC 72-12, Earthquake Engineering Research Center, University of California, Berkeley, 1972.

Seed, H. B. and ve İdriss, I. M.: Soil Moduli and Damping Factors for Dynamic Response Analyses, Report No. EERC 70-10, EERC, University of California, Berkley, 1970.

Vucetic, M. and Dobry, R.: Effect of soil plasticity on cyclic response, American society of Civil Engineering, J. Geotech. Eng., 117, 89-107, 1991.

Yildirim, M. and Savaşkan, E.: A New Approach to the Stratigraphy of the Tertiary Sedimentary Formations in Istanbul and Their Engineering Properties, Proceedings of National Symposium on İstanbul's Geology, Kadir Has University, Cibali-İstanbul, 87-102, 2003. 